\title{
Síndrome de Currarino y enfermedad de Hirschsprung: Una asociación poco frecuente
}

\author{
Dres. David Ibáñez M, Ana Vela M, Beatriz Izquierdo H, Carolina Muel G.
}

Servicio de Radiodiagnóstico, Hospital Universitario Miguel Servet, Paseo Isabel La Católica, Zaragoza, España.

\section{Currarino's syndrome and Hirschsprung's disease: A rare combination}

\begin{abstract}
The Currarino syndrome is an autosomal dominant partial sacral agenesis involving sacral vertebrae S2 to S5, with presevation of the S1 vertebrae. In the most severe form of the syndrome, the sacral agenesis is associated to presacral mass, anorrectal and urogenital malformations. Hirschsprung's disease is a congenital malformation of the hindgut determined by the absence if parasympathetic intrinsic ganglion cells in the submucosal and myenteric plexuses.

We present a case of a 3 years old male child affected from Currarino syndrome associated to Hirschprung's disease.
\end{abstract}

Keywords: Currarino syndrome, Hirschsprung's disease, Presacral mass, Rectal atresia.

Resumen: El Síndrome de Currarino consiste en agenesia sacra parcial de herencia genética autosómica dominante parcial, que afecta las vértebras sacras S2 a S5, preservándose S1. En la forma más severa del síndrome, a la agenesia sacra se asocian masa presacra y malformaciones anorrectales y urogenitales. La enfermedad de Hirschsprung es una malformación congénita del intestino grueso debida a la ausencia de células ganglionares intrínsecas parasimpáticas de la submucosa y de los plexos mientéricos.

Presentamos el caso de un niño de 3 años con Síndrome de Currarino asociado a enfermedad de Hirschsprung.

Palabras clave: Atresia rectal, Masa presacra, Enfermedad de Hirschsprung, Síndrome de Currarino.

Ibañez $D$, et al. Síndrome de Currarino y enfermedad de Hirschsprung: Una asociación poco frecuente. Rev Chil Radiol 2012; 18(4): 175-178.

Correspondencia: Dr. David Ibáñez M. / david_ibi@hotmail.com

Trabajo recibido el 11 de julio de 2012, aceptado para publicación el 30 de octubre de 2012.

\section{Introducción}

El síndrome de Currarino es una malformación congénita poco frecuente en la que, a una agenesia sacra parcial se pueden asociar, en forma de triada, masa presacra, malformaciones anorrectales y urogenitales $^{(1)}$. La enfermedad de Hirschsprung, también se puede asociar a dicho síndrome.

El objetivo de este trabajo es recordar la asociación de ambas entidades así como sus principales hallazgos radiológicos con la finalidad de que el radiólogo, en su práctica habitual tenga en cuenta que ante un síndrome de Currarino con estenosis rectal puede deberse a un Hirschsprung y que en un niño con enfermedad de Hirschsprung debe buscar los otros componentes de la triada de Currarino.

Presentamos el caso de un niño de 3 años. Desde los 2 meses de vida presenta estreñimiento con este- nosis anal (que se describe como de aspecto fibroso a $1 \mathrm{~cm}$ del margen anal) que impide el tacto rectal, realizando dilatación anal a los 6 meses. El paciente es controlado en la consulta de cirugía persistiendo el estreñimiento y la estenosis anal, con ampolla rectal distendida, decidiendo a los 12 meses de vida la realización de cut-back y biopsia de mucosa-submucosa rectal con resultado anatomopatológico de ausencia casi completa de células agangliónicas, siendo diagnosticado de enfermedad de Hirschsprung. Persiste la clínica de estreñimiento y a los dos años y medio de edad se procede a tratamiento quirúrgico vía transanal con ampliación mediante plastia posterior y resección parcial de la zona fibrosa más posterior. Durante dicho ingreso tras enema opaco cuyos hallazgos confirman la sospecha clínica de Hirschsprung (Figura 1) se detecta ausencia de cóccix en la radiografía simple 
de abdomen (Figura 2). Ante la sospecha clínica de médula anclada, el niño fue derivado a nuestro Servicio de Radiodiagnóstico para la realización de resonancia magnética lumbosacra. Los principales hallazgos radiológicos fueron la presencia de cono medular bajo (a nivel L2-L3) que se continuaba con un filum terminale engrosado que se extendía hasta localización presacra, asociado a meningocele (Figuras 3 y 5) y anclado a masa presacra quística con componente graso en su interior, altamente sospechosa de teratoma sacrococcígeo (Figura 4). También se observó agenesia sacra parcial afectando

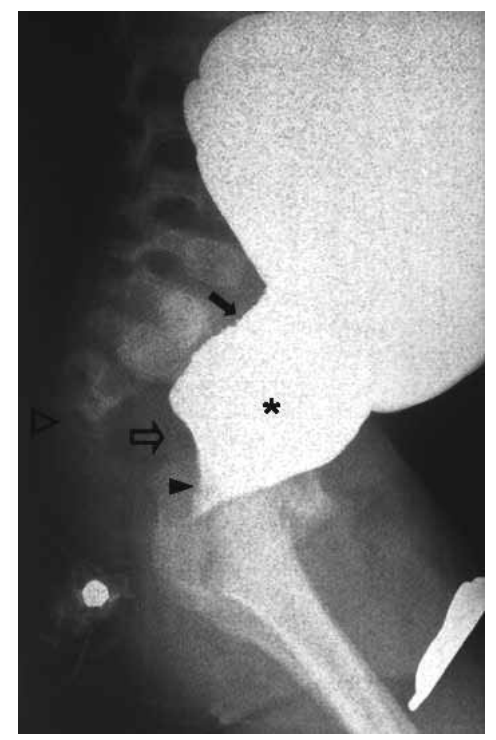

Figura 1. Radiografía lateral abdominal de enema opaco donde se observa evidente dilatación de sigma (*) con aspecto en "torre", de paredes irregulares (flecha negra), de "esfuerzo" con estrechamiento de la zona rectal (cabeza de flecha negra). En espacio presacro se observa efecto masa sobre la pared intestinal (flecha hueca) así como el defecto sacro distal (cabeza de flecha hueca). a cuerpos vertebrales S5 y la mitad derecha de S2, conservándose de S1 a S3. La asociación de estos hallazgos es compatible con síndrome de Currarino.

Además, se visualizó sigma distendido con estenosis anal debidos a la enfermedad de Hirschsprung previamente señalada. El paciente fue intervenido por los servicios de neurocirugía (disección de saco dural terminal, exclusión de cuello de meningocele anterior y sección de filum terminale) y cirugía pediátrica (resección de teratoma sacrocoxígeo de aproximadamente $2 \times 2 \mathrm{~cm}$. localizado por delante de la ampolla rectal) sin incidencias.

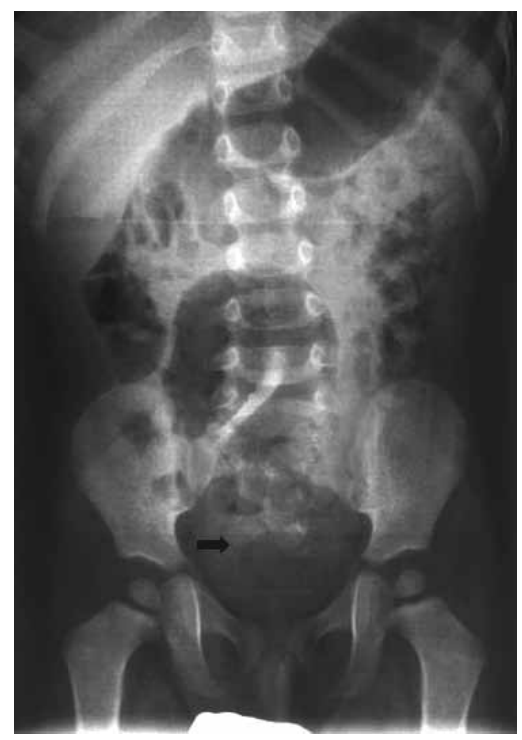

Figura 2. Radiografía simple de abdomen previa a enema opaco donde se observa agenesia de últimos cuerpos sacros (flecha).

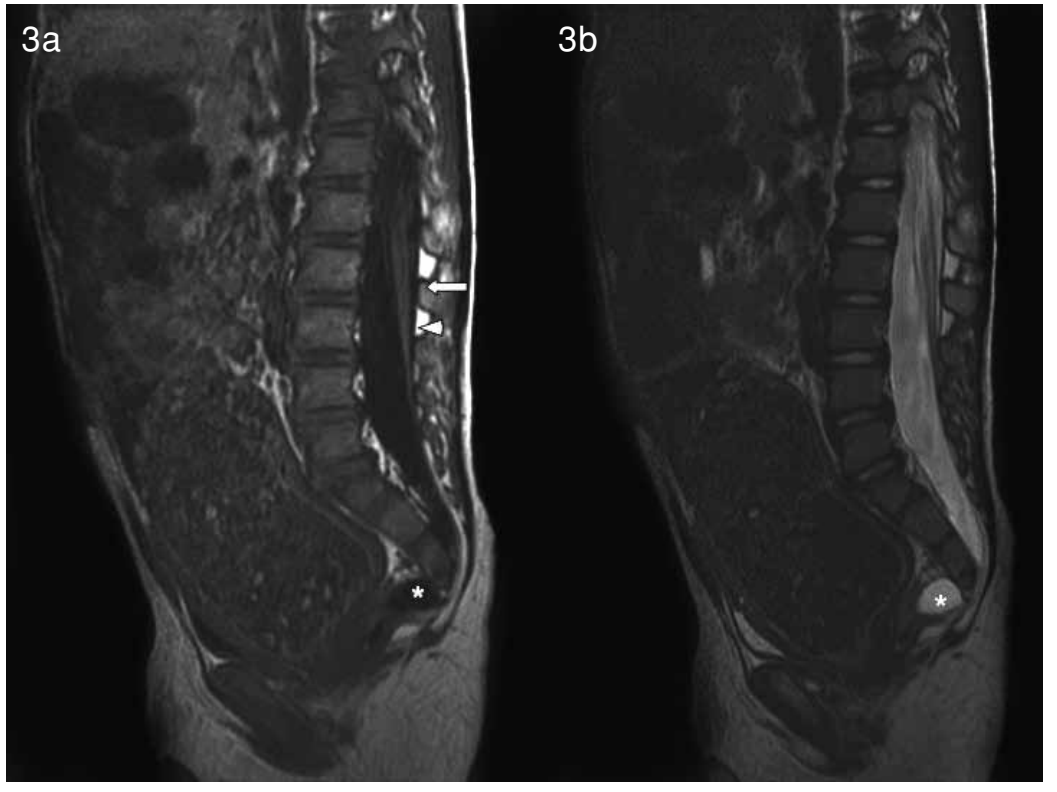

Figura 3. Imágenes sagitales de resonancia magnética potenciadas en T1 FLAIR (3.a) y T2 FRFSE (3.b). Se puede observar un cono medular descendido (nivel L2L3 -flecha blanca-) que se continúa con un filum terminale engrosado (cabeza de flecha blanca). Sólo se detectan los cuerpos vertebrales de S1 a S3 debido a agenesia sacra parcial. En la imagen 3.a se visualiza una masa presacra hipointensa $\left(^{*}\right)$, bien definida, que aparece hiperintensa en la secuencia T2 (3.b). Se informa como meningocele. Además se detecta un sigma distendido y aumentado con estenosis anal en relación con la enfermedad de Hirschprung. 


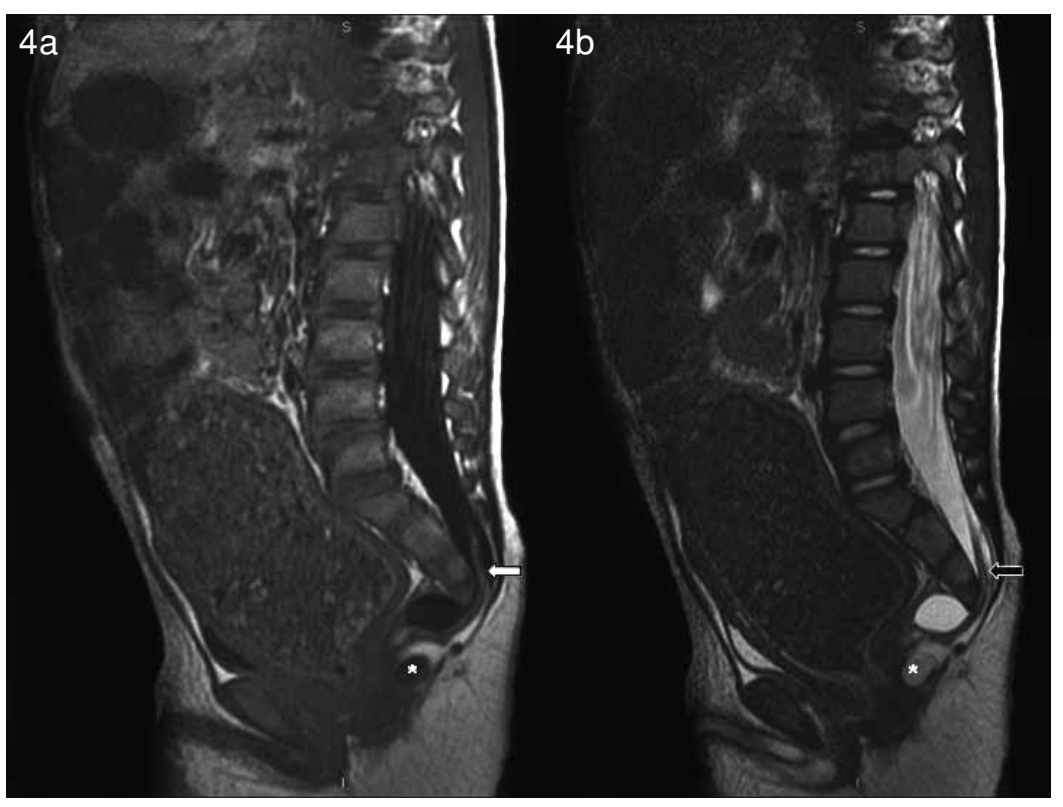

Figura 4. Imágenes sagitales de resonancia magnética potenciadas en T1 FLAIR (4.a) y T2 FRFSE (4.b). El hallazgo principal es el filum terminale engrosado y anclado (flecha) a una masa presacra quística con componente grasa en su interior, próxima al meningocele descrito en la figura 3, altamente sospechosa de teratoma sacroccocígeo $\left({ }^{*}\right)$.

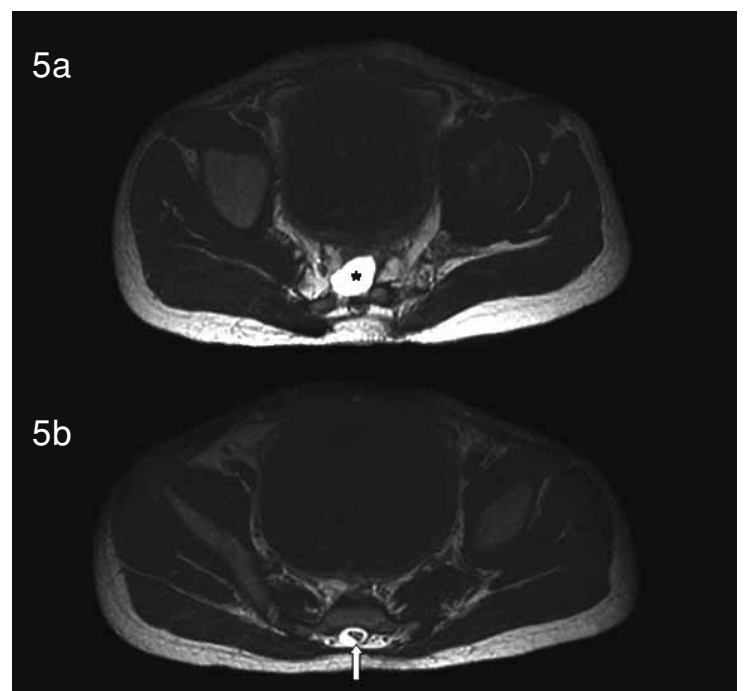

Figura 5. Imágenes axiales consecutivas de resonancia magnética potenciadas en T2 FSE. En la imagen 5a, se observa una masa presacra quística (meningocele *). La imagen $5 b$ muestra el filum terminale engrosado (flecha).

\section{Discusión}

El síndrome de Currarino fue descrito por primera vez por Kennedy en $1926^{(2)}$, pero se establece como una asociación por Currarino en $1981^{(3)}$. Fueron, finalmente, Belloni et al quienes lo denominaron Síndrome de Currarino ${ }^{(4)}$.

Si consideramos la patogénesis, el defecto genético causante del síndrome fue localizado en el cromosoma 7q36 en 1995, encontrando una mutación en el gen HLXB9 en la mayoría de los pacientes con este síndrome ${ }^{(4,5)}$.

Clínicamente, el síntoma principal de estos pacientes es el estreñimiento que aparece desde una edad temprana. La expresividad de la malformación anorrectal va desde la estenosis rectal y ectopia del ano hasta la atresia de éste. Cuando está presente una fístula entre el tracto gastrointestinal y el canal medular, la meningitis es una complicación posible y terrible ${ }^{(7)}$. Anomalías del tracto urinario como la vejiga neurógena, debido a compresión local por una masa 0 a déficit neurológico, son menos frecuentes ${ }^{(8)}$. $Y$ finalmente, la agenesia sacra varía desde desviación lateral del cóccix hasta la ausencia de cuerpos vertebrales sacros distales. Estos hallazgos pueden ser detectados en radiografía simple de pelvis, tomografía computarizada o resonancia magnética.

La enfermedad de Hirschsprung es una malformación congénita del intestino grueso caracterizada por la ausencia de células ganglionares intrínsecas parasimpáticas en la submucosa y en los plexos mientéricos.

La asociación entre la enfermedad de Hirschsprung y las malformaciones anorrectales es rara, con una incidencia del 2,8 al $3,4 \%{ }^{(10)}$, por lo que su concurrencia con el síndrome de Currarino era una posibilidad desde la descripción del mismo. En la literatura actual hay dos casos publicados de su presencia conjunta lo que sugiere que ambas anomalías comparten una patógena embriogenética común ${ }^{(11)}$.

El diagnóstico de la enfermedad de Hirschsprung es a menudo demorado en niños con malformación anorrectal. De hecho es posible que algunos pacientes diagnosticados de síndrome de Currarino con estenosis anorrectal asociada padezcan una enfermedad de Hirschprung no diagnosticada.

Si una estenosis anorrectal, incluida la enfermedad de Hirschsprung, es detectada en un niño, los otros dos componentes de la triada de Currarino deben ser buscados ${ }^{(10)}$ y dichos pacientes deberían ser examinados con placa simple de región pélvica y resonancia magnética lumbosacra(11). Es labor fundamental del médico radiólogo sospechar ambas 
entidades ante los hallazgos descritos, recordar su asociación y recomendar la pruebas diagnósticas necesarias para alcanzar un correcto diagnóstico.

\section{Bibliografía}

1. Lynch SA, Wang Y, Strachan T, Burn J, Lindsay S. Autosomal dominant sacral agenesis: Currarino syndrome. J Med Genet 2000; 37(8): 561-566.

2. Kennedy RLJ. An unusual rectal polyp; anterior sacral meningocele. Surg Gynecol Obstet 1926; 43: 803.

3. Currarino G, Coln D, Votteler T: Triad of anorectal, sacral y presacral anomalies. AJR 1981; 137: 395-398.

4. Aschcraft KW, Holder TM. Hereditary presacral teratoma. J Pediatr Surg 1974; 9: 961-967.

5. Keneflick JS. Hereditary sacral agenesis associated with presacral tumors. Br J Surg 1973; 60: 271-274.

6. Köchling J, Pistor G, Märzhäuser Brands S, Nasir R, Lanksch WR. The Currarino syndrome-hereditary transmitted syndrome of anorectal, sacral and presacral anomalies. Case report and review of the literature. Eur J Pediatr Surg 1996; 6: 114-119.

7. Yates VD, Wilroy RS, Whitington GL, Simmons JCH. Anterior sacral defects: an autosomal dominantly inherited condition. J Pediatr 1983; 102: 239-242.

8. Kirks DR, Merten DF, Filston HC, Oakes WJ. The Currarino Triad: complex of anorectal malformation, sacral bony abnormality and presacral mass. Pediatr Radiol 1982; 14: 220-225.

9. Ross AJ, Ruíz-Perez V. A homebox gene, HLXB9, is the major locus for dominantly inherited sacral agenesis. Nat Genet 1998; 20: 358-361.

10. Baltogiannis N, Mavridis G, Soutis M, Keramidas D. Currarino triad associated with Hirschsprung's disease. J Pediatr Surg 2003; 3(8): 1086-1089.

11. Kilickesmez O, Gol HI, Uzun M, Oruk C. Complete Familial Currarino Triad in Association with Hirschsprung's Disease: Magnetic Resonance Imaging Features and the Spectrum of Anorectal Malformations. Actal Radiol 2006; 47: 422-426.

\section{Su canocimienta está en nuestras manos}

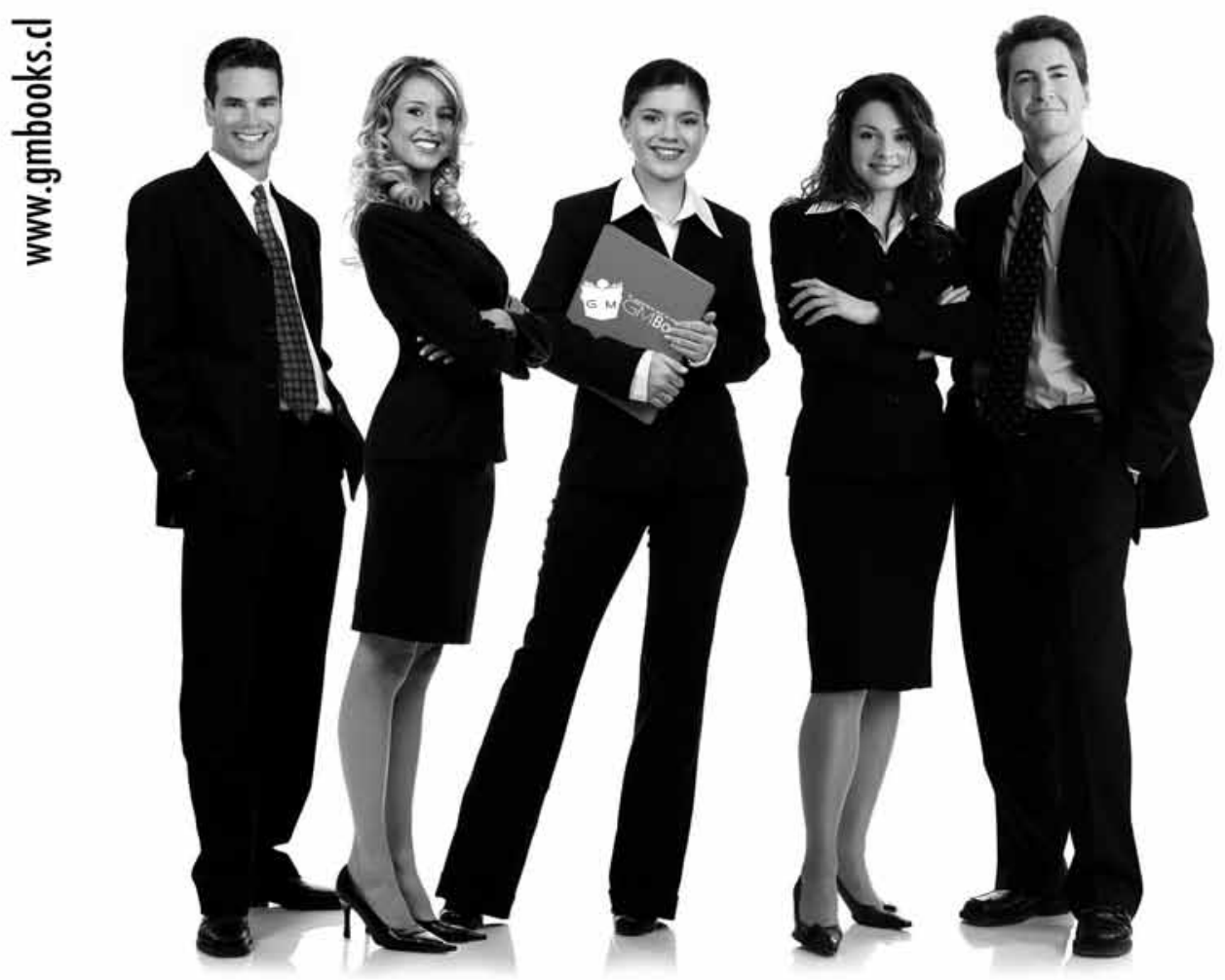

- Arquitectura

- Educación

- Derecho

- Medicina

- Psicología

Aréas

- Economía

- Contabilidao

- Informática

- Comunicación

- Turismo

- Ingeniería

- Arte

- Ciencias Sociales

\section{Distribuidora de libros nacionales e internacionales}

